\title{
The Architect's Essential Instruments: Implications of Affordance Theory for Construction Documentation
}

\author{
LUC PHINNEY \\ Johns Hopkins University
}

To date, architecture has been relatively untouched by the cognitive turn of other disciplines. We may one day talk about 'architectural cognition' or 'cognitive architectonics'; but that day has not yet come. Theorists and some practitioners draw heavily upon the insights of phenomenologists like Martin Heidegger and Maurice Merleu-Ponty, but fewer of them explore the psychological research that influenced those philosophers, and which has continued to evolve since. What use after all is soft science to those who build hard things? Architecture concerns itself with instrumental ends. Yet architects seldom have the hammer physically in hand, or handle the bricks. This can lead to a crisis of confidence. Some architects (famously) overcome this crisis by taking the brick in hand (even, like Hamlet, discoursing with it). Others withdraw from the gritty reality of materials and methods, fomenting figments of fog or fantastically supported glass. But this is not the architect's role. Neither fantasist nor craftsman (however much we may long for the freedom or certainty of those occupations), the architect has, already, a set of tools. But what is their nature? They may be material (if a computer mouse can be considered material-a thorny question!) but are at times less so. This ambiguous relationship to the instrumentality of our instruments renders us less apt to recognize our acts and engagements as conditional upon the limits and possibilities of our tools. One particular concept pervasive in social psychology, J. J. Gibson's theory of affordances, may help us get a handle on the dubious instrumentality of our instruments. A historical example of a building and its tools, constructed by an archaeologist-oftools, will serve as a primary source for this question of the architect's essential instruments.

\section{AFFORDANCE THEORY}

It is perhaps unsurprising that architects are not overly persuaded by the insights of much of the early work on the psychology of perception, which "was, and is, about phenomena that occur when an observer is stationary." ${ }^{11}$ The presuppositions, or framing assumptions, underlying classical psychological research are not a good fit for a discipline which occupies itself with the fabrication of edifices. It is not merely that buildings demand a mobile and engaged perception; additionally, the architect does not so much engage with buildings as extant facts (as might the conservator, assessor, or real estate agent) so much as possibilities, and as purposive acts. This renders many of the early insights of psychological studies irrelevant to the practice of architecture. Fortunately, by the middle of the $20^{\text {th }}$ century, psychologists, in what is often called a 'cognitive turn', began to explore alternatives to the jejune empiricism of their field. Foremost among them were the Charles-and-Ray-Eames-of-midcentury-psychology, J. J., and E. J., Gibson.

After a number of articles in the 1950's and 60's exploring the topic of what he called environmentally situated, or ecological, perception, J.J. Gibson in 1973 authored a paper entitled "The Theory of Affordances". In it, and in the book that would follow in 1979, Gibson formulated what has become one of the most influential theories of perception of the $20^{\text {th }}$ century. ${ }^{2}$ In that paper Gibson introduced the theory he and his wife had been developing for over a decade, coining the term "affordances" to describe way we engage with what we perceive. He began by defining the new term. "The affordances of the environment are what it offers the animal, what it provides or furnishes, for good or ill. The verb to afford is found in the dictionary, but the noun affordance is not. I have made it up. I mean by it something that refers to both the environment and the animal in a way that no existing term does. It implies the complementarity of the animal and the environment."3

Many of the psychologists who took up Gibson's challenge to alter the framing assumptions of their research did so by looking specifically at the effects of being in motion on perception and cognition, replacing the usual laboratory experiments with studies of jugglers, ${ }^{4}$ baseball and hockey players, ${ }^{5}$ and martial artists. ${ }^{6}$ These new research subjects were distinguished by their status as relative experts, as compared to the typical participant in a blind study. Experiments of this type can be difficult to fit in a typical research laboratory, and while attempts have been made to duplicate these findings in a more traditional setting, ${ }^{7}$ the result is often a kinematic study absent absent the factor of expertise. ${ }^{8}$ Many of Gibson's inheritors, while expanding the empirical justification and broadening the application of his claims, echo his studied reticence regarding ways in which the faculties of perception might be altered by a deep knowledge of or familiarity with tools and and environments.

Since at least the mid-1990's researchers have attempted to address this omission by designing experiments involving multiple actors in complex, life-like situations. In related disciplines ethnologists and cultural anthropologists have come at this from the other side, performing deep studies of expertise-in-practice, both in the case of literal hammers and anvils, ${ }^{9}$ as well as the more immaterial pursuits of scientists in 
disciplines such as biological research, explored famously by Bruno Latour in his two year investigation-and-participation with the researchers at the Salk Institute. ${ }^{10}$ Perhaps as a result, the findings of these lines of inquiry have been increasingly influential on other fields. In 1988, the academic and former Apple vice president Donald Norman popularized affordance theory in his bestselling The Design of Everyday Things, the first book to bring these ideas to a broader audience in the design professions.

Affordances, appropriated by Norman from Gibson's work (and the subject of some argument between them ${ }^{11}$ ), would be central to his argument for user-centered design, as "affordances provide strong clues to the operations of things." 12 As Norman revised it, the idea of affordance was not so much an ontological shift, replacing the primacy of objects' empirical properties with their behavioral connotations, as it was a layer of depth added on top of these material properties. For Norman, as for many designers since, questions of ontology were extraneous, and his pragmatism found a ready audience in the design fields. He critiqued the stylistic excesses of modernism, arguing for a more nuanced, behavioral understanding of the designed object. In his follow up book on the topic, Emotional Design, Norman argued that "the best products today, from a behavioral point of view, are often those that come from the athletic, sports, and craft industries, because these products do get designed, purchased, and used by people who put behavior above everything else. Go to a good hardware store and examine the hand tools used by gardeners, woodworkers, and machinists. These tools, developed over centuries of use, are carefully designed to feel good, to be balanced, to give precise feedback, and to perform well."13 (I will return to this tetrad.)

This is where the question of affordances dovetails with instrumentality, and expertise with the topic of tool-use. The best tools are themselves not only objects of design, but designs produced by expert users. Yet many of these designs are old and anonymous, making it difficult to understand how a consideration of their affordances might enrich the projective work of design, and what room full of old tools has to offer the forward-looking designer.

Even more problematic is the question of materiality with regards to our tools. One hundred years ago the architect might have responded to this question by holding up a lead holder or t-square. Today these tools have undergone transformation, and the same keyboard and mouse used to draw construction drawings is a vastly different object, and interpretive tool, from its predecessors. Many architects have lamented the increasing distance between the drawing and the human hand ${ }^{14}$; something that is in this case beside the point. If we think about our tools in terms of the behavior they afford, we can readily see the analogous position occupied by the drafting tools of the $19^{\text {th }}$ century architect, and the architectural 'workstation' of the $21^{\text {st }}$ century. What is the meaning of this variation, this speciation, of tools? If the work is the same, does the instrument matter?

We might find answers-If only we could visit a museum of the metamorphosis of the tool!

\section{AN ARCHAEOLOGIST-OF-TOOLS}

At the dawn of the $20^{\text {th }}$ century in Pennsylvania the industrial revolution had in a generation absolutely transformed the landscape of work and livelihood. It was in this setting that a University of Pennsylvania archaeologist, the soon-to-be former-academic Henry Chapman Mercer, began to discover throughout the countryside fragments of a culture totally unknown to the archaeologists of the time: their own. These evidences included the abandoned tools, jigs, templates, material stockpiles, and unfinished craft objects of the myriad cottage industries pushed to extinction in the closing decades of the $19^{\text {th }}$ century. Mercer would recall this time in his 1915 catalogue of stove plates: "An immense mass of objects became obsolete about 1860 to 1880 and were destroyed, or sold in the so-called 'penny lots,' at innumerable sales to native junk dealers, who, impelled by a desire to find scrap iron, or discover new uses for old things, saved thousands of cast off utensils, and piled up what they did not destroy, in scattered heaps upon their premises."15

One day in the spring of 1897 Mercer was out for a walk in the countryside and came upon a jumble of discarded tools. This was the moment he would later point to as the genesis for his life's work; and what began as a momentary fascination soon become a obsessive impulse to not only collect, but catalogue, the artifacts of these obsolete trades.

It was then probably one day in February or March of the Spring of 1897 that I went to the premises of one of our fellow-citizens, who had been in the habit of going to country sales and at the last moment buying what they called "penny lots," that is to say valueless masses of obsolete utensils or objects which were regarded as useless, or valuable only as old iron or kindling wood, things which fortunately have been preserved among us for two noteworthy reasons, first because of the existence in our country of several of these unthanked and non-mercenary hoarders, and second because of the abundance of wood and consequently of outbuildings, such as are lacking in Europe, adapted to the preservation of perishable heirlooms. The particular object of the visit above mentioned, was to buy a pair of tongs for an old fashioned fire place, but when I came to hunt out the tongs from the midst of a disordered pile of old wagons, gum-tree salt-boxes, flax-brakes, straw beehives, tin dinner-horns, rope-machines and spinning-wheels, things that I had heard of but never collectively saw before, the idea occurred to me that the history of Pennsylvania was here profusely illustrated and from a new point of view. ${ }^{16}$ 
Over time, Mercer built up a collection of tens of thousands of these abandoned tools and implements, until, in 1913, he began work on a 7-story reinforced concrete museum to house the collection. As his biographer, Cleota Reed, would write, Mercer "was among the earliest of serious scholars to recognize the value of the seemingly mundane artifacts of recent history for cultural studies of many kinds." ${ }^{17}$ And the historian Steven Conn proposes that Mercer "applied an anthropological model of cultural change to the process of American historical change."18 Sadly, for Conn the museum Mercer built to house his collection was merely "a bizarre seven-story pile of his own design and made entirely of reinforced concrete" rather than an integral part of Mercer's project. This bias, seeing the museum as a mere container and the tools as the contained, is widespread.

While the museum - still extant and actively pursuing its mission-is often described in impressive, if reductive terms, as a collection of 30,000 items, ${ }^{19}$ it might better be described as 55 vignettes: carefully staged rooms in which Mercer organized his collection of artifacts in an attempt to depict, in each room, the range of artifacts and craft operations utilized in a single trade. This is where the insights of the architectural scholar may perhaps supplement that of the museum historian. When we pay attention to the building itself, rather than merely the items it houses, a clear, and quite prescient, curatorial warrant becomes evident.

Each room in the museum contains the tools associated with a particular trade. Yet this is not a particularly encyclopedic effort. A file-maker's room has many files, including a shelf of "shoemaker's files". The shoemaker's room has rasps and a few files; there are files in other rooms as well. Likewise, a range of drawknives appear in the carpentry, lumbering, and wheelwrighting rooms. Often these tools are arranged around a work bench, or some other primary tool-furniture. These tools are accompanied by examples of the sorts of work they produced. But as Conn notes in his study, neither are these rooms dioramas, because Mercer displays many of the same type of tool side by side. ${ }^{20}$

Mercer's arrangements harken back to a tradition far older that the enlightenment project of the encyclopedia \& the associated, and antedated, material practice of the cabinet of curiosities (to which, it is true, Mercer's museum bears a more-than-passing resemblance). In late Medieval engravings, commonly used as sources for $19^{\text {th }}$ century children's primers (and likely where Mercer would have first encountered them, both in his own youth and in later collecting efforts), ${ }^{21}$ we often see depicted a craftsperson in a small room, surrounded by the tools of their trade. [Fig 1.] This tendency, to depict trades as vignettes of craft activity carried out in a confined but architecturally articulated space crowded with tools, was a cultural norm that grew in popularity from the

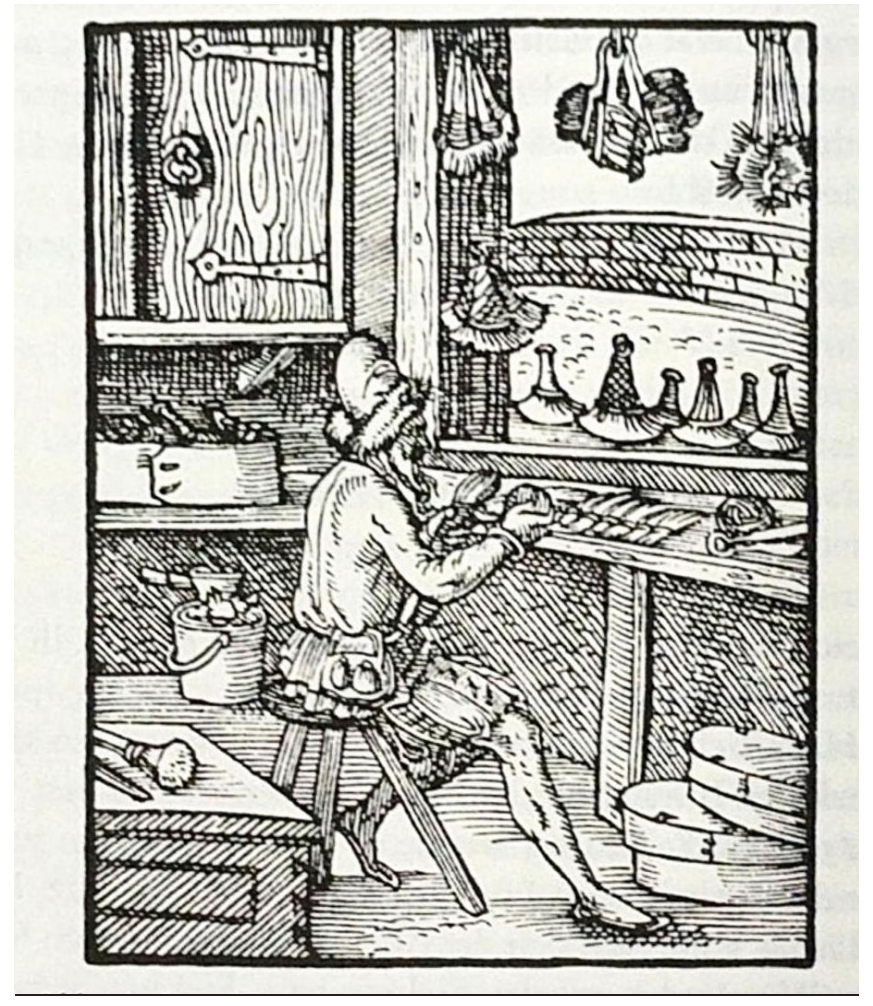

Figure 1. Der Burstenbinder und sein Sortiment, (Brush binder and his assortment). Ca. 13th c. Image: Public Domain. Source: Lexikon des Alten Handwerks

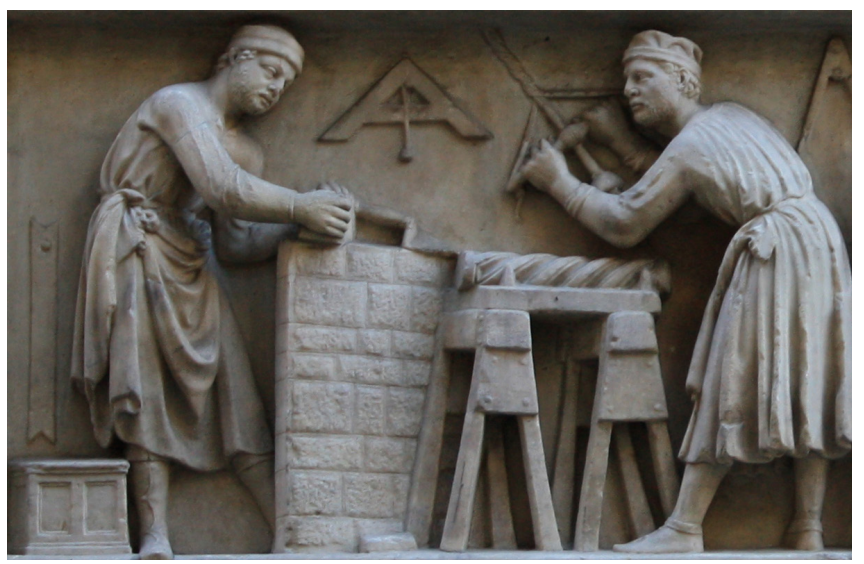

Figure 2. Nanni di Banco: 1408. Detail from The Four Crowned Saints, Orsanmichele, Florence. Image: Dan Philpott CC 2.0 Attribution

late middle ages onwards, utilized even in the ornament of buildings. [Fig 2.]

'Vignette', however, may be a misleading term, as it implies the creation of a scene-of-work. In these engravings the intent is certainly to an extent scenographic: here is the artisan at work. Yet there is also a didactic element. Even at first glance these depictions do not show just those tools than might be visible in any purely representational depiction of a workshop. These are not photographs of the place of work so much as catalogues, narrative framings-one might even say technographies-of a craftsperson's tool-afforded work. 
A 1568 woodcut attributed to Hans Sachs shows a potter in his pottery. [Fig 3.] In it, the story of the potter's craft is told in chronological order from the right background to the left foreground. In the distance a woodsman cuts wood, which is in the next moment fed into the open mouth of a kiln. Closer, but still outside the workshop window, a man digs clay, the folded earth beginning to pile up beside him. Inside to the potter's right a pile of clay sits on the floor, while the potter sits facing left with his hands on an unfinished vessel and his foot turning the kickwheel below. Extending from a shelf next to the wheel to the front of the frame are vessels increasing in decoration and variety as they crowd into the foreground. (There are also, inscrutably, what look to be cosmological, or perhaps geometrical, treatises in the potter's direct line of sight.) In this image we see a clear narrative development, laid out in the non-perspectival three-dimensional space of the illustration.

The rooms of Mercer's museum possess a similar narratively structured disposition of materials. As an early museum curator described the pottery room:

In the room devoted to pottery craft there are two potters' wheels-one an XVIII Century type, in the background. One of these wheels has a very complete set of the hand tools used in the "throwing" of jars or pitchers or bowls etc. At the left is a pug mill, with extra irons, used for grinding and mixing clay. In the foreground are two querns, mainly for grinding glaze materials. There is also a miscellany of moulds, materials used in firing the kilns, also finished and partly finished pottery. ${ }^{22}$

All of these items are displayed in close proximity. Interpretive signage is now extant, but was not part of the original display. ${ }^{23}$ On the table surface of the potter's wheel, ribs and jigs sit adjacent to finished pots, whose curves reflect but are not identical to those of the forming tools, suggesting the causal relationship without making a specific claim about this bowl and this rib. [Fig 4.] Their arrangement moves from the potters wheels and tools on the right to the partially finished ware directly adjacent to them. To the left, shelves of finished glazed ware show the range of possibilities open to the traditional redware potter. This storytelling arrangement is repeated in the various rooms of the museum. The result, then, is a visual synopsis of the world of work, a broad range of the craftsperson's actions at various sites with various tools. Mercer's vignettes participate in this sort of narrative summation. Yet more is going on here than storytelling.

Mercer's vignettes do something else as well. Unlike the above engravings, rather than showing one representative tool for each type of craft activity Mercer shows us at times 10 or 20 variations on the same implement. It is as if he wants to materialize not one tool's singular use, but rather the larger context of affordances ${ }^{24}$ within which that tool-type is situated, revealing the trajectory of innovation and refinement, the diversity and ultimately the cosmogony of a particular craft activity. [Fig 5.]

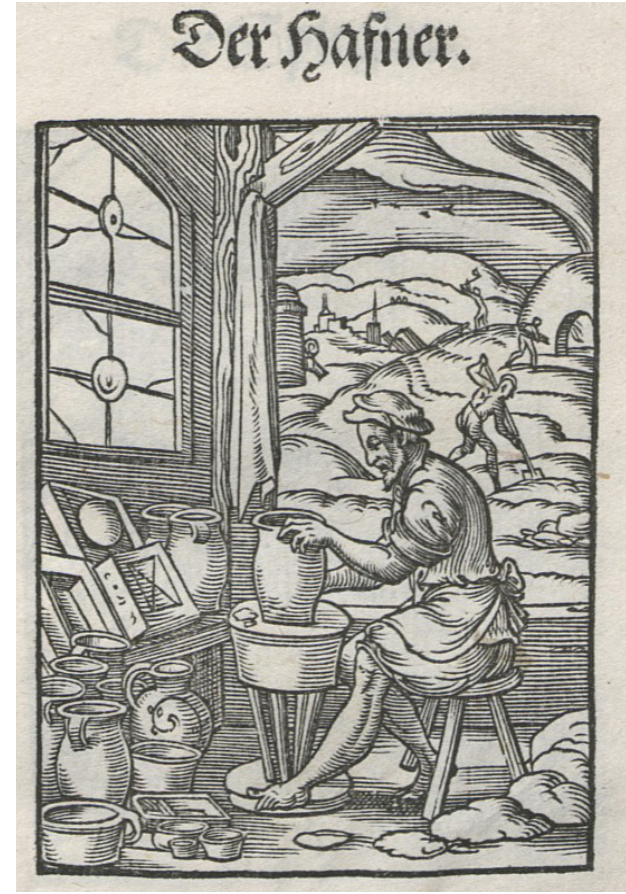

Figure 3. Der Hafner. Image:Public Domain Source: Deutsche Fotothek

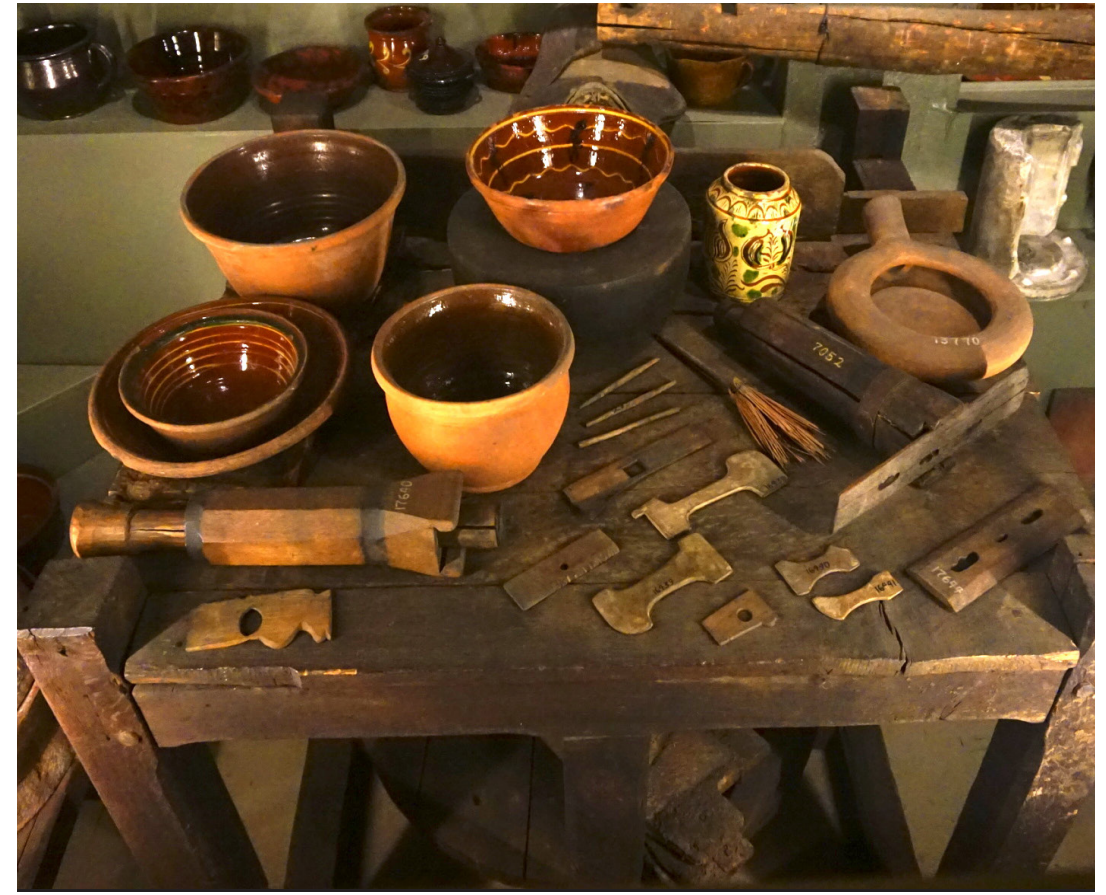

Figure 4. Pottery room, Mercer Museum. Image: Author 


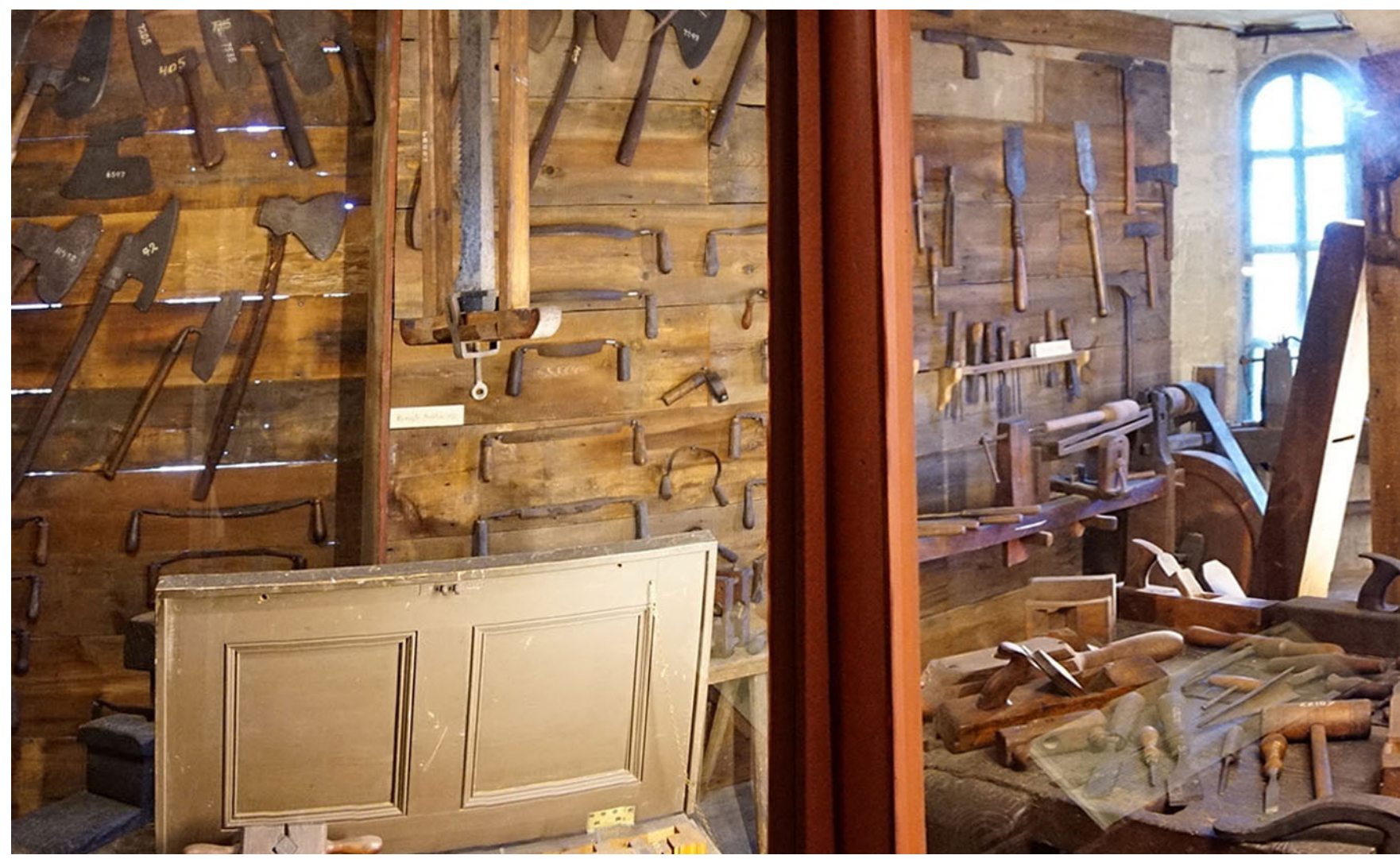

Figure 5. Carpentry Room, Mercer Museum. (Images stitched to show more of the interior space.) Image: Author

This is not so much a story about vignettes of tool use, as it is a story of the lives of craft activities. It is a story that could only be told from an archaeological point of view, in which the iterations of tools make visible the evolution of practice. Mercer's rooms do not show the evolution of one tool-type; but rather of a constellation of tools, co-evolving together as the needs of the work grow and change. Further, these vignettes reveal the degree to which we take as axiomatic the materiality of our tools. Yet they point to an underlying nature that is not abstract; and yet not material: tools are the lexicon of craft actions. ${ }^{25}$

\section{TOOLS IN THEIR CONTEXT OF AFFORDANCES}

Mercer's rooms attempt to materialize this lexicon, showing tools not merely as individual objects or evolving types, but in their broader context of affordances and interrelationships. Dutch philosophers Erik Rietveld and Julian Kiverstein, in their 2014 essay The Rich Landscape of Affordances, address the question of a context of affordances directly. Architects, they argue, use affordances (knowingly or not) to solve design problems. ${ }^{26}$ This is a significant expansion of Gibson's original premise, which described affordances as belonging to the realm of perception (prior, that is, to deliberative decision-making), and inhering in objects. The object-oriented affordances of Donald Norman were very much in keeping with this view. But Rietveld and Kiverstein want to propose that immaterial things create affordances too, such as uses of language or representations.
"Language," they write, opens up the possibility to be held to account by other people in our community for what we say and do. We argue that these practices of giving and asking for reasons can also be made sense of in terms of skilled engagement with affordances. Abilities and practices like these typically have not been recognized as within the scope of investigation in ecological psychology. It is a virtue of our framework for understanding affordances that it can also be applied to allegedly "higher" human abilities, such as the capacity to make correct perceptual judgments, an ability that is fundamental to propositionally articulable forms of knowledge. For instance, when we are out looking for mint leaves to make mint tea and a friend incorrectly reaches for a nettle we can stop him or her by making the judgment, "That is not a mint leaf; that is a nettle." In doing so we are skillfully engaging with the affordances the nettle leaf has in our form of life[.]

Rietveld and Kiverstein's insight here is that the affordances of nettle leafs, teapots, and hammers are inextricably bound up in the social net of using and making. But their claim is more specific than merely that human communication is integral to the affordances of objects. Human communication, or more specifically "propositionally articulable forms of knowledge" are no less instrumental than material tools.

We can thus consider the possibility of propositional affordances-that is, affordances produced by linguistic structures, 
including the conditional and subjunctive. This is the precise grammatical configuration of the architectural construction document. That is to say, we can call the construction document a tool in the hands of an expert because it, like the material artifacts we are more wont to imagine, is activated by and activates the stock of craft knowledge relevant to the tasks it describes. The tool engages the tool user in a context of affordances (a 'room') belonging to a particular trade. The construction document engages its expert user in just the same way. ${ }^{27}$

The sociologist Alfred Schutz described how this occurs in practice, as the act of 'projecting', or making anticipatory plans, ${ }^{28}$ activates "the stock of knowledge actually at hand, which is, thus, the sedimentation of previous experiencing acts together with their generalizations, formalizations, and idealizations. It is at hand, actually or potentially recollected or retained, and as such the ground of all our protentions and anticipations." ${ }^{29}$

The theory of affordances tells us something important about the nature of our tools. First, that a good construction document functions just like a hand tool, by populating the site of the work with affordances. This is its essential function; and if we look at the way a construction set is used on a typical job site-with excerpts passed out to various trades; revision clouds taped over outmoded information; an index copy kept up to date in some location of central reference-it is clear that it functions as a primary tool in the building's realization. Together, the architect and the contractor fabricate and use this tool in a nonce collaboration and improvisation. ${ }^{30}$

Second, seen in light of Mercer's museum of tools, the theory of affordances suggests that when designing our tools we should remember that there is a historical trajectory in which the tool at hand has evolved, and that its affordances are conditioned upon past iterations of the same tool. A new tool is adopted when it expands the affordances available to the user, and even tools vastly different in appearance may afford very similar things. On the other hand we should distinguish clearly between those tools used to make drawings, whether it is $21^{\text {st }}$ century CAD or the $19^{\text {th }}$ century centrolinead, and those used to make buildings, as these belong to different contexts of affordances, and innovations tend to be incremental, whatever their morphological novelty, within established "rooms" ${ }^{31}$

\section{IMPLICATIONS}

If we suppose the construction document, then, may act as a primary tool (or "chief tool") of the architect in the making of buildings, and bridge between the disciplinary nexus of the office and the craft actions of the jobsite, then much of the recent innovation in the tools of our representational technology, driven as it is by advances in information technology, and located wholly within the office of the architect, would seem to be in service of ends extraneous to those of economical and effective construction documentation. BIM may suit some buildings, and some firms, better than others, not because of any flaw in the firm or the design but rather because it, as presently constituted, provides some affordances with dizzying facility (product specification, for example), and renders others wholly inaccessible to the designer. (Often these priviledged affordances carry external baggage.) As information technology continues to move us from mice to touchscreens and from desktops to "augmented" reality, we may see alterations to the standards of practice far more substantial than those that have occurred between Sutherland's invention of the digital "Sketchpad"32 and today's networked jobsites. This is because, as we see with Mercer's tools, so few of our graphical innovations, aimed as they are at producing the same old construction drawings, offer truly new affordances. Instead, we labor with circumscribed tools to make available the same context of affordances provided by the maylined and mylar drawings of generations past. If we recall Norman's tetradthat our designs are pleasurable, balanced, responsive, and functional, we can see how poorly the construction document functions as an object of design. It is not so much that it lacks the Vitruvian virtues-and here we might read pleasure as Venustas, functionality as Utilitas, and balance as Firmitas-as that they so poorly provide Norman's fourth virtue, what he calls "precise feedback." Perhaps it is time to ask what our new technologies might newly afford; and how the instruments of representational activity might interpenetrate with those of building-and ultimately engage more fully with the lexicon of craft activities and their work.

The architectural theorist Marco Frascari wrote episodically about the relationship between technology and architecture, if only rarely directly about tools. In one such instance, he proposed

that a productive approach to critical research in architecture is possible only if the complexity of the technological image is preserved. This is possible only through a radical change in our understanding of the role of drawings in architecture. Drawings must become technographies. These are graphic representations analogously related to the built world through a corporeal dimension and embodying in themselves the Janus-like presence of technology in architecture, where the techne of logos cannot be separated from the logos of techne. As specific acts of demonstration, these technographies are based on an architectural encyclopedia, which is a thesaurus of technological images. ${ }^{33}$

We can design better buildings by thinking about the affordances they provide. Buildings can serve; they can also tell us how to work more efficiently, play more readily, live more fully. The buildings that fail, that are imploded in a cloud of rising concrete dust, are buildings that fail to provide a basic context of affordances. The buildings that succeed do more than provide a programmed set of activities-they provide for a much 
broader context of affordances, presumably including actions the original designer never considered.

But affordance theory can be applied to more than the conception of good buildings. It should propose to us, as designers, that we reconsider the nature of our tools. Frascari proposed that our drawings-our technographies-belong in a corporeal context. This is the realm of tools. Yet, today, despite our many new tools, the drawings and specifications we architects create with all this new and advanced equipment-our tools for building with-are much the same ones we made a hundred years ago. Like many of Frascari's coinages, I am not sure what a 'thesaurus of technological images' might look like. But we might begin with the image of a museum of craft activities, a narrative catalogue of the possibilities of building; and we might consider how the challenges of the next century will provoke us to alter that collection of practices.

The challenge I would to raise for those of us who undertake study and research in the field is this: that we invent not merely new tools; but new rooms.

\section{ENDNOTES}

1 James G. Greeno, “Gibson's Affordances," in Psychological Review 101, no. 2 (1994): 336-342, 336

2 See James Jerome Gibson, The Ecological Approach to Visual Perception (Boston: Houghton Mifflin, 1979). Gibson's influence was particularly evident in the 1990's, as the 1986 republication of his 1979 work found a wide audience. Psychological Review published a 1994 special issue dedicated to his Affordances theory, and while none of its exponents have to date received a Nobel prize for their work, one did receive an IgNobel for his work on HulaHooping. (Michael Turvey in 2004.)

3 Gibson 1979, 127. Gibson's work is presaged by Merleu-Ponty's 1945 Phenomenology of Perception.

4 Michael T. Turvey, Richard C. Schmidt and Peter J. Beek. "Fluctuations in Interlimb Rhythmic Coordination." In Karl M Newell, Daniel M Corcos, Variability and Motor Control (Champaign IL: Human Kinetics Publishers, 1993). 381-411.

5 Claire F. Michaels and Raul R. D. Oudejans, "The Optics and Actions of Catching Fly Balls: Zeroing Out Optical Acceleration," Ecological Psychology 4, no. 4 (1992): 199

6 Motoki Okumura, Akifumi Kijima, and Yuji Yamamoto, "Perception of Affordances for Striking Regulates Interpersonal Distance Maneuvers of Intermediate and Expert Players in Kendo Matches." Ecological Psychology 29, no. 1 (Jan, 2017): 1-22

7 Jeffrey B. Wagman and Claudia Carello, "Affordances and Inertial Constraints on Tool Use." Ecological Psychology 13, no. 3 (2001): 173

8 It is interesting to note the degree to which psychologists able to overcome the subject-object dichotomy with with regard to kinematic experience retain a materialist skepticism regarding differing levels of past experience with regards to the task at hand. Perception and memory would seem to be difficult to reconcile in the stricter variations of the empiricist worldview. Or perhaps the methodological norms of their discipline make such a subject hard to test and verify.

9 Charles M. Keller and Janet Dixon Keller, Cognition and Tool Use: The Blacksmith at Work. Learning in Doing (Cambridge England;New York: Cambridge University Press, 1996).

10 Bruno Latour and Steve Woolgar, Laboratory Life : The Construction of Scientific Facts (Princeton, N.J.: Princeton University Press, 1979).

11 See the introduction to Norman's later book revisiting the topic, Emotional Design. In Donald A. Norman, Emotional Design: Why we Love (Or Hate) Everyday Things (New York: Basic Books, 2004).

12 Donald A. Norman, The Design of Everyday Things [Psychology of everyday things] (Basic pbk ed. New York: Basic Books, 1988), 9.

13 Norman 2004, 82

14 See Williams and Tsein's essay, On Slowness, or Marco Frascari's 2011 Eleven
Exercises in The Art of Architectural Drawing: Slow Food for the Architect's Imagination.

15 Henry C. Mercer, Horace Michener Mann, and the Bucks County Historical Society, Doylestown. The Bible in Iron; Or, Pictured Stoves and Stove Plates of the Pennsylvania Germans (Doylestown, Pa.: The Bucks County Historical Society, 1941), 182 (note 36)

16 Henry Chapman Mercer, and The Bucks County Historical Society,"Tools of the Nation Maker" In A Collection of Papers Read before the Bucks County Historical Society, volume 3, (1909): 471.

17 Reed, 17.

18 Steve Conn, Museums and American Intellectual Life, 1876-1926 (Chicago: The University of Chicago Press, 1998), 173.

19 "About." Mercer Museum website. Accessed March 22, 2017.

20 Conn, 172.

21 Mercer discusses this at length in his numerous remarks on Faktur, sprinkled throughout his collection catalogues. See Tools of the Nation Maker (1897).

22 John Cummings (Curator of Mercer Museum) First Draft for Mercer Museum book, dated Aug 17th 1957, papers of BCHS. 24-25. This can be found in manuscript in Mercer's papers held at the Spruance Library.

23 Sadly, several of the trades are not housed in their original rooms, having been relocated by earlier generations of museum curators. The museum was originally intended to follow an arrangement with what Mercer termed "primary" tools ("weaving", "lumbering") in the lower levels and "secondary" tools ("weapons", "music"). See A Classification of Historic Human Tools. This is a single printed broadsheet and can be found in Mercer's papers held at the Spruance Library.

24 I do not want to claim that Mercer had physicalized 'affordance theory' decades before its formal development-these sorts of anachronic claims, while often satisfying, are historiographically flawed. And while it is true that some of the earliest seeds of these theories may have been planted in Mercer's mind, such as John Dewey's bridging of philosophy and anthropology that would find fruit in his seminal 1915 Democracy and Education, Mercer pursued his efforts relatively independently of these converging strains of intellectual history. Mercer may have been exposed to the theories of John Dewey through his friend and client Queene Ferry Coonley, an educator and proponent of Dewey's ideas who would would commission works not only from Mercer but some years later from Frank Lloyd Wright. Mercer, however, did not keep any of Dewey's works in his library and does not directly reference Dewey's aesthetics in his journals. Still, the congruence between these two thinkers is remarkable, and may well have been part of their participation in a larger zeitgeist or intellectual community. It would seem Dewey was fascinated by many of the problems that confronted Mercer as well. As Theodora Polito wrote in her study of Dewey and Vico, "Instead of looking for the origins of the modern mind in the aesthetic, more precisely the myth, Dewey looks for the origins of the modern mind in the original occupations and industries of ancient people." See Theodora Polito, "Educational Theory as Theory of Culture: A Vichian Perspective on the Educational Theories of John Dewey and Kieran Egan," Educational Philosophy \& Theory 37, no. 4 (2005): 475-494.

25 And, symmetrically, craft actions are the semantics of tools. The organizational theorist Arthur Stinchcombe makes a similar argument about construction drawings. See Arthur L. Stinchcombe, When Formality Works: Authority and Abstraction in Law and Organizations (Chicago: University of Chicago Press, 2001).

26 Erik Rietveld and Julian Kiverstein, "A Rich Landscape of Affordances," Ecological Psychology 26, no. 4 (2014):36.

27 Mercer's organizational chart mentioned above included provisions for the 'tools' of the lawyer, architect, and school teacher. Very few of these trades, unfortunately, have received vigorous curatorial treatment in his museum; nor do their artifacts and documents figure substantially in Mercer's original collection. This may have been because these 'trades' were not in the process of wholesale transformation when he undertook his collection efforts; or rather, that their changes were rather more organizational than instrumental.

28 Anticipatory plans can here be read as a homologue for the construction document in its subjunctive construal by the architect (rather than in its nominative use by the builder)

29 Schutz, Alfred. Collected Papers 1: The Problem of Social Reality. Phaenomenologica, 11 (The Hague: Nijhoff, 1962), 146. Emphasis mine.

30 Improvisation as a core architectural activity is something I discuss elsewhere.

31 Fascinating, in this context, is Mercer's predilection for reinforced concrete construction, a building technology which at that time had no established craft practice - and indeed, received no room in his museum.

32 For a novel revisitation of Sutherland's role in the origins of CAD, see Daniel Cardoso Llach, "Algorithmic Tectonics: How Cold War Era Research Shaped our Imagination of Design," Architectural Design, Vol. 83 (2013): 16-21.

3333 Marco Frascari, "A New Angel/Angle in Architectural Research: The Ideas of Demonstration," Journal of Architectural Education 44, (1990): 11. 